\title{
A reescrita do texto literário de alunos dos anos iniciais da escolarização
}

\section{Rewriting literary texts of students from initial school grades}

\author{
Angela Mari Gusso ${ }^{1}$ \\ Elisa Maria Dalla-Bona²
}

\begin{abstract}
RESUMO
Analisam-se os processos de reescrita de textos com propósito literário produzidos por alunos de $4^{\circ}$ ano do ensino fundamental, numa escola da Rede Municipal de Ensino de Curitiba. Os textos, mesmo depois de revisados pela professora, permanecem com um potencial inexplorado, considerando que as orientações para a reescrita se limitaram aos problemas gramaticais e/ou ortográficos. A qualidade aquém do desejável em relação ao efeito estético dos textos deve-se, principalmente, à falta de oportunidade para o aluno-autor testar os efeitos de sua escrita com os colegas de classe e/ou o professor, e de reescrevê-lo visando aprimorá-lo no sentido de obter uma aproximação maior com as características do texto literário.
\end{abstract}

Palavras-chave: reescrita; produção textual; texto literário; ensino fundamental.

\begin{abstract}
We analysed the rewriting process of texts produced with literary purpose by fourth grade elementary school students from Curitiba, Brazil. Rewritten texts retained unexplored potential even after teacher revision, once rewriting was usually limited to grammar and spelling correction. Text aesthetic effect of substandard quality was due, in great part, to the lack of opportunity of the
\end{abstract}

DOI: $10.1590 / 0104-4060.36316$

1 Pontifícia Universidade Católica do Paraná. Escola de Educação e Humanidades. Curitiba, Paraná, Brasil. Rua Imaculada Conceição, nº1155. CEP: 81611-970.

2 Universidade Federal do Paraná, Setor de Educação. Curitiba, Paraná, Brasil. Rua General Carneiro, $\mathrm{n}^{\circ}$ 460. CEP: 80060-150. 
student-author to test the effects of his text on fellow students and teachers and to rewrite it aiming at improving it to achieve literary text characteristics.

Keywords: rewriting; text production; literary text; elementary school.

\section{Introdução}

No ano de 2009, uma das autoras deste artigo observou, por mais de 80 horas, o trabalho com o texto literário desenvolvido em uma turma de $4^{\circ}$ ano (crianças entre 9 e 10 anos de idade) de uma escola da Rede Municipal de Ensino de Curitiba, que atende alunos dos meios sociais menos privilegiados. A pesquisadora contou com a sensibilidade do corpo docente da escola, que permitiu sua presença como observadora das atividades realizadas com a literatura nessa sala de aula.

A pesquisa ${ }^{3}$ foi de natureza etnográfica, pois implicou uma longa permanência em campo e a ênfase não foi no produto final, mas no processo, "na formulação de hipóteses, conceitos, abstrações, teorias e não na sua testagem" (ANDRÉ, 2005, p. 30). Foram estudados os processos pedagógicos desenvolvidos pelo professor e seus efeitos para os alunos, trazendo à tona o que tem sido e o que precisa ser feito na escola para a formação de leitores e do aluno-autor (TAUVERON, 1996).

As técnicas utilizadas, associadas à etnografia, foram: observação, análise de documentos e entrevista. As observações ocorreram de forma passiva, não havendo qualquer intervenção por parte da pesquisadora, que registrou os dados, detalhadamente, em diários de campo. O principal documento examinado foi o caderno das crianças, permitindo uma análise minuciosa de suas produções escritas. As entrevistas com professores e alunos foram gravadas, e as informações obtidas por meio delas foram articuladas às dos diários de campo e dos documentos analisados, num esforço de aproximação das impressões do pesquisador, dos professores e dos alunos.

O objetivo geral da pesquisa foi analisar uma experiência escolar com o letramento literário, processo que envolve leitura e escrita de literatura. A utilização do termo escrita literária para referência aos escritos dos alunos revela

3 Detalhamento da pesquisa pode ser consultado em: DALLA-BONA, Elisa Maria. Letramento literário: ler e escrever literatura nas séries iniciais do ensino fundamental. $334 \mathrm{f}$. Tese (Doutorado em Educação) - Programa de Pós-Graduação em Educação, Universidade Federal do Paraná. Curitiba, 2012. 
nossa crença no potencial do aluno-autor, na sua capacidade de criar efeitos no seu texto, deixando espaços em branco e lacunas a serem preenchidas pelo leitor, de provocar suspense e surpreender o leitor, de demandar sua coautoria. Mas, ao mesmo tempo, por se tratarem de textos produzidos por crianças que estão em fase de familiarização com as características do texto literário e em fase inicial de aprendizagem da escrita de narrativas com uma intenção artística e estética, fica a ressalva de que, desse modo, tais textos não estão sendo tomados aqui como literários, no sentido pleno dessa palavra, mas com potencial para uma escrita literária, ou com teor literário.

Diversos textos ficcionais produzidos pelos alunos durante as observações foram fotocopiados, porém, neste artigo serão apresentados apenas aqueles que passaram pelo processo de reescrita. Essa opção deve-se ao fato de haver fartura de publicações relativas à leitura literária, por outro lado são escassas aquelas sobre a escrita literária e raras as sobre reescrita. O objetivo deste artigo é o de, a partir do material recolhido, apontar caminhos para a utilização da reescrita como um processo de reflexão e de aprimoramento da produção escrita dos alunos-autores.

\section{A importância da reescrita na formação do aluno-autor}

A ênfase dada pelo professor à aprendizagem dos conhecimentos gramaticais, lexicais, ortográficos e dos sinais de pontuação nas aulas de produção do texto ficcional acaba por induzir o aluno a uma concepção equivocada sobre o ato de escrever. Não há dúvidas sobre a relevância da aprendizagem das regras de funcionamento da língua escrita, mas a fonte motivadora para o aluno iniciar a escrita literária não está nesse aprendizado, senão no acesso ao conjunto de obras da literatura.

O ponto de partida para se chegar à produção de textos literários é a leitura, mas não qualquer leitura. Excluem-se aquelas de gêneros textuais oriundos de outras esferas, uma vez que os textos empíricos pertencentes a um dado gênero textual apresentam características relativamente estáveis (BAKHTIN, 1992). Portanto, trata-se de oferecer aos alunos dos anos iniciais os exemplares do universo da literatura infantil que se caracterizam pela densidade de seu conteúdo, por sua força emotiva potencial, pelo humor, pela capacidade de romperem o horizonte de expectativas do leitor, por se deixarem abrir de maneira plural e, ainda, porque suas palavras e frases plurívocas, seus não ditos ou vazios, suas ambiguidades e contradições são suscetíveis de uma leitura polissêmica (TAUVERON; SEVE, 2005, tradução nossa). 
A escrita literária se organiza na intertextualidade, ou seja, nas relações que estabelece com outros ditos. No caso da criança pequena, como essa experiência é ainda restrita, acredita-se que, num primeiro momento, o importante seria ela ler muito e, aos poucos, começar a escrever com a mediação do professor, a fim de ir apreendendo os recursos disponíveis na língua para criar a trama da história, ou o que Lecuyer (1992) ${ }^{4}$ chama de fio da meada, e assim evoluir para explorar as estruturas narrativas, os efeitos das palavras e atender ao que Jay (2007) denomina intenção artística e estética.

Embora o texto literário se caracterize por dar maior liberdade ao autor para manifestar seu estilo, a criatividade para produzir formas inusitadas de dizer é alcançada por aqueles que têm bom manejo da língua, condição atrelada a um processo de interlocução e de mediação que, na escola, cabe ao professor assegurar. No caso de textos ficcionais, a apreensão de sua arquitetura (tema, intriga, ponto de vista, narrador, personagem, estrutura, sequenciação, coerência, verossimilhança, espaço e tempo) depende de um trabalho sistematizado, embora isso não signifique que o caminho consista em apresentar aos alunos tais elementos composicionais e, em seguida, levá-los a redigir mecanicamente.

A produção de textos escritos, independentemente do gênero textual a que pertençam, conforme apontado por Fiad (1991), envolve três momentos recursivos: planejamento, escrita propriamente dita e reescrita(s). No caso de contos ficcionais, sua produção também depende de planejamento, portanto, antes de o aluno-autor se lançar na escrita propriamente dita, fazendo-se necessária a construção de um roteiro do texto, momento reservado para, com a mediação do professor, ele pensar sobre os rumos da narrativa e nos efeitos que pretende provocar no leitor.

Tal como o planejamento, faz parte ainda do processo de escrita o momento da revisão textual, que leva à(s) reescrita(s). No ato de revisar, pela mediação do outro, aprende-se sobre o funcionamento da língua e, particularmente, no caso de reescrita de histórias, sobre as estratégias que resultam na obtenção do efeito estético. Esses conhecimentos vão se aplicando às revisões seguintes, portanto, tratando-se de um momento importante para a construção de saberes que possibilitarão ao aluno-autor atuar com maior autonomia em situações de escrita posteriores, além, é claro, de possibilitar o aprimoramento do texto em processo de produção.

Não raro, na escola, a reescrita se limita a uma atividade mecânica com ênfase nos problemas gramaticais e/ou ortográficos. Porém, a partir de uma concepção dialógica de linguagem, ou seja, considerando seu caráter sócio-histórico, sua natureza interacional e seu uso social, a reescrita torna-se uma

4 As traduções das obras estrangeiras foram realizadas livremente pelas autoras. 
atividade por meio da qual o professor consegue interagir com os textos dos alunos apontando possibilidades de ajustá-los aos objetivos pretendidos pelo aluno-autor e à forma de dizer (relativamente estável) do gênero em questão.

Muito mais do que solucionar problemas de ordem gramatical ou ortográfica, a reescrita de um texto ficcional serve para mostrar ao aluno-autor, por exemplo, que certas informações do texto precisariam ser mais detalhadas, complementadas, para a obtenção dos efeitos de sentido pretendidos; que uma reordenação dos segmentos textuais contribui para a sequência da história fluir com maior clareza e coerência; que certas informações, por não estarem contribuindo com o desenrolar da trama, devem ser suprimidas; que certos segmentos precisam ser substituídos para a concretização do projeto de dizer; que determinadas escolhas lexicais serão mais fecundas para efeitos polissêmicos. Vale destacar que no caso de textos com propósito estético, a busca pelas formas mais apropriadas demanda um intenso trabalho de garimpagem dos recursos disponíveis na língua.

Nesse sentido, fica evidenciada a importância de o professor redimensionar seu papel para aquele que estabelece permanentemente o diálogo com os alunos e estimula as parcerias entre eles, para que, em conjunto, aprendam a driblar a sinuosidade do texto literário, busquem construir sentidos para o que leem e desenvolvam a capacidade de produzir textos com teor literário.

A reescrita como procedimento pelo qual o professor e os colegas de turma auxiliam o aluno-autor a pensar sobre por que escreveu determinado conteúdo e o fez daquela maneira tende a motivar o aluno-autor a retomar seu texto com o propósito de resolver os problemas identificados no momento da revisão.

Desvignes (2000) ressalta a importância de o aluno perceber que uma escrita bem feita exige reescrita e que escrever consiste em trabalhar e retrabalhar o texto fazendo balanços e tentativas, realizando escolhas relevantes e incorporando as mais expressivas, até que o produto obtido o satisfaça.

\section{Análise de experiências com a reescrita}

As questões indicadas acima serão agora retomadas para análise da experiência com reescrita na escola onde a pesquisa foi realizada. Asseveramos que o despertar para a produção do texto literário está na leitura de textos instigantes. No caso daqueles que serviram de referência para os textos dos alunos (Thor; O reizinho mandão; Drimz, uma história de podes e não-podes), pode-se afirmar que apresentam uma boa qualidade literária e são capazes de 
provocar o imaginário e a fantasia das crianças. Aos alunos, portanto, sempre foram solicitadas escritas a partir de leituras efetuadas individualmente ou em voz alta pela professora, e na realização de todas elas demonstraram motivação, fato confirmado neste fragmento de uma entrevista com a professora da turma:

Pesquisadora - Você considera que as crianças correspondem as suas expectativas na realização das atividades?

Professora - Sim, com certeza, com essa turma foi um trabalho bem bom, porque tudo o que você propunha para eles, eles gostavam e faziam com dedicação e não tinha nenhum "ah eu não quero fazer", "eu não gosto" ou "eu não pude fazer". Às vezes eu dizia "vamos rápido" dai eles não iam, eles estavam lá tentando fazer com riqueza de detalhes.

As limitações constatadas nos textos dos alunos não se devem, portanto, à falta de motivação ou ausência de intertextualidade, mas a fatores relacionados à exploração do texto lido no momento de sua análise, à formulação da proposta de produção e/ou à condução da reescrita.

\section{Thor}

A professora leu para os alunos uma história da mitologia nórdica intitulada Thor. O personagem é um deus, excelente guerreiro, dono de um martelo com o qual domina o trovão e de um cinturão mágico que duplica sua força. Sua missão é manter a salvo e em ordem o mundo dos deuses e dos humanos, combatendo os gigantes e a grande serpente do caos, Jörmungand.

Abaixo transcrevemos a página de um caderno contendo a atividade de reescrita proposta pela professora e também a produção do aluno, que serão analisadas na sequência.

Releia o trecho do texto:

Thor obedeceu e chegou o mais rápido possivel. Entrou no palácio voando e rodando seu martelo mágico no ar.

- Quem é esse hóspede que perturba a casa do meu pai? - Perguntou. 
Reescreva o trecho como se Thor estivesse contando o acontecimento.

Resposta: Eu obedeci e cheguei o mais rápido possivel. Entrei no meu palácio voando e rodando meu martelo mágico no ar.

- Quem é esse hóspede que perturba a minha casa? - Perguntei.

Nesse caso, não se trata de uma produção textual a partir do texto lido, mas de uma atividade objetivando a sistematização das possibilidades de escolha do foco narrativo para a construção do texto, sem dúvida, um conhecimento de peso relevante para a produção de textos ficcionais. Entretanto, a atividade ficou descontextualizada, pois se restringiu ao fenômeno da passagem do discurso indireto ao direto e, consequentemente, o aluno não chegou a perceber as implicações de uma narrativa em primeira ou em terceira pessoa, decisão importante quando se trata de escrita literária.

Apesar de o conhecimento sobre os modos como um narrador pode apresentar os acontecimentos ser importante para a leitura e produção de histórias fictícias, a atividade proposta aos alunos, por ter se restringido apenas ao nível linguístico-gramatical, não lhes permitiu perceber a diferença entre a voz do narrador que não toma parte dos acontecimentos e daquele que também é personagem da história. Observa-se, portanto, que a questão do ponto de vista não foi, de fato, objeto de análise nessa atividade.

Uma possibilidade de exploração do foco narrativo seria solicitar aos alunos que reescrevessem uma história completa pelo olhar de Thor, personagem envolvido na trama. Porém, haveria a necessidade de, anteriormente, as crianças já terem lido e comparado contos escritos em primeira e em terceira pessoas para verificarem a diferença entre os efeitos resultantes de uma e de outra estratégia narrativa. No caso do foco narrativo em terceira pessoa, o narrador é alguém que está fora da história, vê e ouve tudo, desse modo, sabe de tudo. Por outro lado, o narrador em primeira pessoa relata os acontecimentos de um ponto de observação limitado, porque o faz a partir daquilo que pensa/ julga ter acontecido. Tratam-se, portanto, de estratégias distintas com diferentes impactos na construção textual.

No caso de a história ser narrada pela perspectiva do personagem Thor, poderiam surgir reescritas muito criativas revelando, talvez, as possíveis inseguranças e dúvidas do poderoso herói, com grandes chances de serem estimulantes e despertarem o interesse do leitor. Uma atividade como essa exigiria a resolução de um problema pelos alunos e daria sentido à atividade de escrever, muito além da mera preocupação com a concordância verbal. 


\section{O reizinho mandão}

A professora leu para os alunos $O$ Reizinho Mandão, de Ruth Rocha. No conto, com a morte de um rei, assume o trono seu filho, garoto muito mimado que se divertia fazendo leis absurdas. Seu excesso de egoísmo e sua arrogância provocaram tamanho pânico que as pessoas deixaram de falar. Quando ele passou a ficar incomodado com esse silêncio, procurou se aconselhar num reino vizinho, com um velho sábio que o orientou a procurar em seu próprio reino uma menina que ainda falasse. Ao retornar, ele encontra uma menina que o enfrenta e o manda calar a boca. A partir disso, todos voltam a falar, mas o reizinho não aguenta o barulho e vai embora.

Para a atividade de análise textual foi colado no caderno dos alunos o trecho da história com as leis absurdas criadas pelo reizinho: "Fica terminantemente proibido cortar a unha do dedão do pé direito em noite de lua cheia!" e "É proibido dormir de gorro na primeira quarta-feira do mês." Para a produção de texto, o enunciado apresentado foi o seguinte:

\section{Leis absurdas}

O reizinho fazia leis absurdas para seus súditos. Crie leis bobas, engraçadas, esquisitas, para divertir seus leitores.

Conforme se pode verificar, no enunciado, há um título, "Leis absurdas", seguido de um comando para a criação de leis. A orientação não fornece todos os elementos necessários para serem levados em conta na prática de produção textual, comprometendo assim seu planejamento. No momento de planejar o texto, é essencial que o aluno-autor tenha claras para si - tal como acontece nas mais diferentes situações de escrita nas práticas sociais - as condições socioverbais a que o texto estará vinculado, ou seja: o assunto, o propósito/intenção do texto, o gênero que lhe permite realizar seu propósito de dizer, o leitor previsto, bem como o suporte onde será publicizado.

Considerando-se que no enunciado da tarefa a orientação dada é no sentido de se elaborar leis absurdas, supõe-se que os alunos escreveriam um conjunto de frases organizadas em itens, nos moldes de um regulamento. No entanto, pode-se verificar nos textos apresentados, a seguir, que eles escreveram uma história na qual um personagem detentor de poderes sobre seus súditos cria leis “bobas, 
engraçadas, esquisitas". Esse fato deveu-se à orientação oral da professora, no momento da atividade, para que criassem as leis no contexto de uma narrativa.

As leis esquisitas 5

Em uma tarde, o reizinho entediado, chamou seus súditos e ordenou que todas as tardes fizessem palhaçadas. Os súditos não gostaram mais concordaram. Outro dia esse reizinho mandou todos trabalharem de pijamas bizarros, todos acharam um absurdo mais tiveram que atende-lo. Esse reizinho com essas ideias até mandou que não podia comer verduras e legumes só porque não gostava, mais ainda bem que os súditos fizeram ele mudar de ideia.

Mais o pior foi quando ele fez todos até seus súditos, até as mulheres pintarem o cabelo de verde, ai é que fez todos ficarem com raiva dele.

Até que um dia veio uma menina bonita, no seu reino e brigou com ele, ele ficou apaixonado e parou de fazer leis bizarras em seu reino.

O aluno-autor é bem-sucedido ao começar a história com a voz narrativa situando os acontecimentos em um tempo remoto (Em uma tarde) na vida de um reizinho. Muito interessante foi a fórmula encontrada para relacionar o personagem com o reizinho da história original, pois, ao invés de reafirmar que ele era mandão, a informação é a de que ele estava entediado e, sem ter o que fazer, inicia seus desmandos, o que faz o leitor inferir seu autoritarismo.

No original, o povo tem medo do reizinho e, diferentemente da história do aluno-autor, não o contraria. É criativa a opção de os súditos não gostarem, acharem um absurdo e ficarem com raiva das leis do reizinho e, por falta de alternativa, se submeterem, mas em determinado momento fazerem-no mudar de ideia. Como não houve oportunidade de o aluno-autor ler o texto para os colegas para, assim, contar com a análise e sugestões da classe e do professor, o potencial do texto deixou de ser explorado. Ele poderia ter sido orientado a separar em três o primeiro parágrafo e detalhado o porquê de os súditos não terem gostado de fazer palhaçadas, o porquê de acharem um absurdo atender aos desmandos, o que fizeram para o reizinho mudar de ideia quanto à proibição de comer verduras e legumes, e, por fim, esclarecer como o personagem acabou se apaixonando por uma menina que brigou com ele. Portanto, a maior fragili-

5 Não foram feitas alterações ou correções nas transcrições, todas elas são transcrições fiéis do caderno dos alunos. 
dade do texto deve-se ao fato de as soluções serem abruptas ou não terem sido explicitadas; devido a essa lacuna, dificilmente conseguirá envolver um leitor.

$\mathrm{O}$ aprimoramento desse texto em atividades de reescrita poderia ter ocorrido também dos pontos de vista gramatical e ortográfico: corrigindo-se a grafia da conjunção mas, acentuando a forma verbal atendê-lo ( $3^{\mathrm{a}}$ frase), arrumando a concordância do verbo poder ( $4^{\mathrm{a}}$ frase), acentuando a palavra aí. Além disso, solucionando-se a repetição das palavras tarde ( $1^{\mathrm{a}}$ frase), reino e ele (último parágrafo).

Em relação ao final da história, a fórmula arrojada de súditos insubordinados poderia propiciar uma surpresa no desfecho, inclusive por inspiração no original, que termina deixando um mistério sobre o paradeiro do reizinho. Porém, observa-se uma repetição da fórmula desgastada do final feliz: o reizinho, apaixonado, deixa de criar leis bizarras.

\section{O dono de seu reino ${ }^{6}$}

Era uma vez um principe de 11 anos chamado Luiz ele gostava de pegar um pergaminho fazer leis loucas exemplo: "Todos devem ter um cavalo em casa". es as entrega ao conselheiro e dizia que era do pai dele, e lá o conselheiro passava a maior vergonha.

¥Num serto dia o conselheiro disse ao rei:

- Que leis são essas?

- Que lei, estou a 2 meses sem dar lei!

- Olhe o pergaminho!

Ele leu a lei mais louca do mundo.

O rei deixou o prinsipe de castigo até os 13 anos.

A história original inicia-se com a morte do rei. De forma muito inventiva, o aluno-autor cria uma história que ocorre num período anterior, enquanto o rei ainda estava vivo. A opção por incluir a relação entre pai e filho mostra-se totalmente inusitada; também é original o mau caráter do reizinho, que tenta enganar o pai. O final é, ao mesmo tempo, alentador - imaginar que ele foi punido e colocado no seu devido lugar - e enigmático - o que teria acontecido com o reizinho depois do castigo? Teria ele aprendido a ser uma pessoa melhor?

Esse texto, assim como o anterior, tem todo um potencial inexplorado. O aluno-autor foi criativo, mas não teve a oportunidade de testar os efeitos da

6 Texto transcrito conforme a redação do aluno. 
sua história com os colegas de classe e/ou o professor, e de reescrevê-lo com o intuito de aprimorá-lo, por meio do acréscimo de detalhes a fim de criar um clima de suspense e a história se tornar mais envolvente, da revisão e emprego dos sinais de pontuação para assegurar maior clareza ao texto, da correção dos desvios da norma ortográfica de algumas palavras e mesmo para avaliar a pertinência do título escolhido.

\section{Drimz, uma história de podes e não-podes}

Drimz, uma história de podes e não-podes, de Rosana Rios, tem 46 páginas e, portanto, impossível de ser lida em apenas uma aula. A professora utilizou três diferentes momentos para lê-la aos alunos que, por gostarem muito de ouvi-la, logo que chegavam à sala de aula, cobravam dela a continuidade da leitura.

A história, que trata de seres da mitologia e ligados aos elementais da terra, se passa, resumidamente, assim: Lu encontra-se no jardim com uma gnoma, chamada Drimz; elas contam uma à outra suas histórias de vida. Lu fala do seu cotidiano com a família e o quanto vivia cercada de não-podes; já as histórias de Drimz são sobre sua vida como um dos elementais da terra, espíritos existentes na natureza. Explica que os gnomos são pequenos humanoides que vivem sobre a terra, que as sílfides são fadas do vento; as náiades, ninfas aquáticas, e as salamandras são elementais que representam o fogo. Conta que sentia grande admiração pelo Mestre Gromz, o gnomo mais sábio de todos, que orientava o seu desenvolvimento, mas que teve de partir quando a floresta foi dominada pelos faunos. A partir de então, a vida deles era tanto "não-pode" que todos os espíritos da natureza se revoltaram. Para resolver o problema, as sílfides provocaram um vendaval na floresta que espantou os faunos permitindo o regresso de Mestre Gromz. A história termina com Drimz encorajando Lu a esquecer os "não-podes" e cuidar dos "podes".

Com o intuito de que os alunos lessem o livro, a professora organizou um rodízio entre eles usando os dois exemplares de que dispunha, de modo que ao final de um mês todos haviam lido a obra. Então, a professora pediu para que fizessem, oralmente, uma síntese e comentários sobre o livro. As crianças disseram ter gostado da história "por causa dos reinos elementais como água, fogo, ar e terra e os tipos de seres de cada um deles, e por ter sido divertida a leitura de um enredo engraçado e envolvente".

A atividade escrita decorrente da história foi a seguinte: 
Faça de conta que o mestre Djim Gromz resolveu lhe fazer uma visita. Que aventura vocês dois irão viver? Dê um título à sua história.

A professora lembrou à classe que ao escreverem deveriam respeitar os parágrafos e travessões nos diálogos. Advertiu que, na produção do texto, não era para resumir a história lida, mas para criar outra. Os alunos redigiram os textos, que foram corrigidos pela professora, e depois os reescreveram. Para este artigo, selecionamos dois para analisar. $\mathrm{Na}$ transcrição optamos por destacar entre parênteses as correções feitas pela professora.

\section{A aventura de Mestre Gromz}

Um dia, quando mestre Gromz estava andando pelo jardim, ele escutou um barulho mas muito grande.

Era a formação de um elemento novo, era o metal. Esse elemento do metal pegou boa parte do território do elemento (do) terra, ele (. ELE) tinha uns 300 soldados (COMANDADO?) por grande mestre Zeus, que era gigante!

Drim que era eu, (et) estava junto com mestre Gromz o (*O) exércitos de (Z)Seus me capiturou e todos do meu elemento o (. O) que não foi capiturado, foi mestre Gromz, e ele fugiu.

Mestre Gromz nesse periodo estava recuperando seus poderes para lutar comtra (CONTRA) Zeus.

Mestre Gromz (VOLTOU) derrotou o exército (DELES) e te) me salvou (. ASSIM,) com os meus poderes e do Mestre Gromz derrotamos Zeus e recuperamos nosso valle.

(* PARÁGRAFO)

(BOM TEXTO! REFAÇA OU REESCREVA-O FAZENDO AS DEVIDAS CORREÇÕES.)

O fato de a professora ter gostado do texto e sugerido apenas algumas pequenas alterações ortográficas (não corrigiu todas) dão indícios sobre o que ela valoriza na produção textual dos alunos. Uma análise um pouco mais detalhada em relação aos aspectos literários indica que eles são ignorados por ela.

A narrativa do aluno perde o rumo em diferentes momentos denunciando que não houve um planejamento textual. No $2^{\circ}$ parágrafo, quando a terra é dominada pelo novo elemento, o metal, não fica claro quem é Zeus; somente 
no $3^{\circ}$ parágrafo percebe-se que esse personagem é um oponente. As soluções são abruptas, fato que dificulta ao leitor a compreensão do desencadeamento das ações, não ficando explicado, por exemplo, como se deu a volta do mestre Gromz ou como ele salvou Drim.

Apresentar esse texto para a turma e promover uma discussão coletiva desses aspectos seria uma excelente oportunidade para os alunos observarem as especificidades dos textos ficcionais e desmistificarem a reescrita percebendo as operações que, de fato, essa atividade envolve.

Observe-se que a narrativa apresenta elementos capazes de empolgar ao envolver os personagens em situações dramáticas e provocar suspense, como acontece, por exemplo, quando Mestre Gromz é surpreendido por um barulho muito grande devido à criação de um novo elemento, pela presença do gigante Zeus e seu exército de 300 soldados, pela captura de Drim, a fuga e a volta de Mestre Gromz, com a união das forças de Drim e Mestre Gromz na luta contra os inimigos e na recuperação do vale. No entanto, esse potencial não foi explorado e perdeu-se a oportunidade de a atividade de reescrita ter se constituído em um momento para o professor orientar o aluno no sentido de melhor estruturar a narrativa, uma habilidade essencial para a produção de textos com propósito literário. $\mathrm{O}$ fato de a professora ter considerado como um bom texto e apontado apenas problemas de ordem mais pontual, acabou por reforçar no aluno-autor sua convicção de que escrever/reescrever restringe-se aos cuidados com os aspectos ortográfico e gramatical.

\section{Uma aventura com o conhecimento}

Eu estava em minha casa quando apareceu o mestre Djim Gromz. Ai eu me lembrei que pedi para ele vir, me contar sobre suas histórias.

De repente ele me puchou (PUXOU) e flutuamos pelas nuvens!

Ele me mostrou que é o ar que faz (FAZ) nos faz respirar (, ) ai eu perguntei:

- O ar é igual ao vento? E ele me disse:

- Não Amanda (, ) o vento tem movimento e o ar não.

Ai ele ia falar sobre o fogo quando eu interrompi dizendo:

- Ixi! Eu não gosto do fogo, ele queimou toda a casa da minha tia!

- Bom (, ) o fogo faz isso mais também tem suas coisas boas como aquecer, esquentar a comida e outras coisas. É eu concordei e assim (e assim DEPOIS) ele ia falar da água.

- Ah! Essa tem bastante funções e assim me empolguei falando:

- A água serve para beber, para tomar banho, lavar as roupas, para me divertir nos dias quentes de verão e outras coisas. Assim ele (Assim . ELE) falou: 
- Parabéns (!) e que (eque. Que) bom que você sabe e (e. MAS) não se esqueça, nada de gastar ela! (ma de gastar eta! DE NÃO GASTÁ-LA DEMAIS.)

Por último a terra (. - É) é dela que nasce (NASCEM) as árvores e flores e etc.

Depois dessa aula voltei para minha casa e começei (COMECEI) a reparar mais funções nesses 4 elementos para a próxima visita do mestre Djim Gromz.

(* PARÁGRAFO)

(BOM TEXTO, REESCREVA-O ARRUMANDO OS ERROS.)

Este texto também foi considerado bom pela professora e nele há poucas indicações de correções ortográficas. A aluna-autora demonstra domínio dos recursos gráficos para a inserção do diálogo, um elemento característico das narrativas, porém a questão problemática do texto refere-se ao seu conteúdo, definido por Soares (1999) como didatizado e pedagogizado, ou seja, não apresenta aspectos constituintes da literariedade. O enredo está marcado pelos ensinamentos da área das ciências, não há aventura e os personagens são monótonos e previsíveis: Mestre Gromz se assemelha muito a um professor enquanto Amanda é a aluna boazinha. Os momentos em que poderia haver alguma empolgação, como no segmento em que a personagem conta que o fogo queimou a casa da tia ou quando menciona as brincadeiras de verão com a água, são interrompidos pelos ensinamentos de preservação ambiental e bom comportamento, revelando que a aluna supõe ser oportuno inserir na história conteúdos aprendidos nas aulas, por sua provável valorização pela leitora prevista - a professora.

\section{Considerações finais}

A análise das atividades de produção de textos ficcionais na escola evidenciou a importância da reescrita no processo de desenvolvimento da competência de escrita, porém não como exercício mecânico de correção ortográfica e capaz apenas de gerar alteração apenas nos aspectos da superfície do texto.

$\mathrm{Na}$ escola, foram priorizadas escritas para atender a uma demanda da professora, e não para a formação do aluno-autor, pois desconsiderou-se que um autor se constrói porque ele procura seu leitor (GONZÁLES, 2009), que é essencial aprender a não dizer tudo e muito menos imediatamente, mas dis- 
seminar indícios (TAUVERON; SEVE, 2005) e, ainda, apreender estratégias para explorar as potencialidades da literariedade do texto, isto é, os recursos estéticos responsáveis pela sedução do leitor.

Portanto, não basta ao professor propor a leitura de uma história interessante, é preciso, também, orientar o plano do texto a ser redigido: refletir sobre os personagens, as situações vividas por eles e as estratégias mais apropriadas para seduzir o leitor. O esboço antecipado dos rumos da narrativa evitam problemas que comprometem a coerência na ordenação dos fatos narrados na história. Além do planejamento, há que se considerar que o texto não fica pronto na sua primeira versão. Ao contrário, a primeira escrita do texto não passa de um rascunho que depende, como afirmam Ferreiro e Siro (2010), de variadas instâncias de revisão. As autoras sugerem uma primeira revisão em dupla, que permite uma exposição inicial a um colega e com um tempo de reflexão mais prolongado. Para os alunos-autores que desejarem, passa-se para uma análise coletiva do seu texto, com as contribuições dos colegas e do professor. Com isso, visa-se a favorecer uma reflexão sobre o potencial e os limites do texto em foco, além da organização pelo aluno-autor do seu planejamento de reescrita.

O importante é que a reescrita seja uma opção assumida pelo aluno-autor, por ele ter tomado consciência das alterações que se fazem necessárias em seu texto e desejar incorporá-las. A probabilidade de isso acontecer será maior se as propostas de produção textual formuladas pelo professor levarem em conta que todo texto escrito prevê a existência de leitores. São esses leitores potenciais que, indiretamente, estimularão o aluno-autor a buscar um texto de maior qualidade.

\section{REFERÊNCIAS}

ANDRÉ, M. Estudo de caso em pesquisa e avaliação educacional. Brasília: Líber Livro Editora, 2005.

BAKHTIN, M. Estética da criação verbal. São Paulo: Martins Fontes, 1992.

DESVIGNES, M. La littérature à la porte des enfants. Enjeux des ateliers d'écriture dès l'école primaire. Paris: L'Harmattan, 2000.

FERREIRO, E.; SIRO, A. Narrar por escrito do ponto de vista de um personagem. Uma experiência de criação literária com crianças. São Paulo: Ática, 2010.

FIAD, R. A escrita como trabalho. In: MARTINS, M. H. (Org.). Questões de linguagem. São Paulo: Contexto, 1991, p.55-62. 
GONZÁLES, A. La construction de la posture d'auteur dans les projets littéraires: écrire de la littérature pour apprendre la littérature. REPÈRES - recherches en didactique du français langue maternelle. Revue de l'Institut National de Recherche Pédagogique. Lyon, n. 40, p. 201-225, 2009.

JAY, B. Il faut un coeur pour un homme comme pour une histoire. De L'observation du «sujet scripteur» à l'école élémentaire. In: BISHOP, M.; ROUXEL, A. (coordoné par). Sujet lecteur, sujet scripteur, quels enjeux pour la didactique? Revue le Français Aujourd'hui, Paris, A. Colin, p. 83-93, 2007.

LECUYER, C. Écrire et lire à l'école élémentaire. In: ORIOL-BOYER, C. (sous la direction de). Ateliers d'écriture. Grenoble: L'Atelier du Texte, 1992, p. 169-180.

SOARES, M. A escolarização da literatura infantil e juvenil. In: EVANGELISTA, A. et al. A escolarização da leitura literária: o jogo do livro infantil e juvenil. Belo Horizonte: Autêntica, 1999. p. 17-48.

TAUVERON, C. Des «pratiques d'évaluation» aux «pratiques de révision»: quelle place pour l'écriture littéraire. REPÈRES - recherches en didactique du français langue maternelle. Revue de l'Institut National de Recherche Pédagogique. Lyon, n. 13, p. 191-210, 1996.

TAUVERON, C.; SEVE, P. Vers une écriture littéraire ou comment construire une posture d'auteur à l'école de la GS au CM. Paris: Hatier, 2005.

Texto recebido em 28 de abril de 2014.

Texto aprovado em 03 de maio de 2014. 